\title{
RETINOPATHY OF PREMATURITY MATERNAL AND NEONATAL RISK FACTORS SCREENING FOR RETINOPATHY OF PREMATURITY
}

\author{
S. Tzvetkova ${ }^{1}$, Sv. Nikolova ${ }^{2}$, E. Kontrova ${ }^{2}$ \\ University of Medicine Varna, Chair of Obstetric and Gynecology ${ }^{1}$, Chair of Ophthalmology ${ }^{2}$
}

Reviewed by: Assoc. Prof. T. Mitov, MD, PhD

\begin{abstract}
Retinopathy of prematurity (ROP) is a disorder of the blood vessels in the developing retina of premature infants, and is one of the major causes of blindness and impaired vision among children. Screening for ROP detect infants needing treatment for ROP and decrease the risk of most severe forms Aim: To review the antenal and postnatal risk factors, associated with ROP, evaluate the current screening guidelines in our neonatal intensive care unit and present the results of his application Materials and Methodes: Over the ten -years period from 1996-2005, 686 neonates were screened for ROP. The first examination for ROP is at four weeks of postnatal age. The criteria to include in the screening are: birth weight less than 1500 g.; gestational age ?32 weeks; neonates between $1500-2000 \mathrm{~g}$. and $>32$ weeks, who required supplemental oxygen therapy/ mechanical ventilation for more than 7 days or those with instable clinical course. The changes of ROP are classified according to the International Classification of Retinopathy of Prematurity. Resultes: The total number of ROP cases was $143(20,85 \%)$, with mean birth weight $1319,5 \mathrm{~g}( \pm 323)$ and gestational age $30( \pm 2)$ weeks. We compare the outcomes of screening examinations and treatment for two study periods: from $1996-2000$ and from 2001 - 2005. Mild ROP (stages 1 and 2) was found in 7,14\% (49/686) and severe ROP (stages 3 - 5) in $13,7 \%(94 / 686)$ of the examined infants. Discussion: ROP is a multifactorial disease. Short gestation and low birth weight increase the risk of ROP. Other identified risk factors include sepsis, IVH, RDS and mechanical ventilation. Although supplemental oxygen is a significant risk factor for ROP. The incidence of ROP and the severity of the disease are not changed significantly in the two five-years periods, but the study's 10 years follow-up report confirmed these lasting benefits: unfavorable structural outcomes were reduced from $41,56 \%$ to $13,51 \%$. Conclusion: The rate of severe ROP and the need for therapy decrease significantly in association with the use of adequate pulse oxymetry monitoring equipment and the implementation of a strict clinical practice of oxygen administration and management in VLBW infants Screening program and guidelines for ROP were accepted in our neonatal intensive care unit 10 years ago. We consider that our experience can be use for the elaboration of national screening guidelines for ROP.
\end{abstract}

Keywords: Retinopathy of prematurity, risk factor, screening

Increased survival of extremely low birth weight infants (ELBW), due to advances in antenatal and neonatal care has resulted in a population of infants at risk of developing retinopathy of prematurity (ROP). ROP has been recognised as an important cause of childhood visual impairment and blindness since the 1940s when impoved facilities and treatment increased the survival rate of premature infants. Although its incidence and severity have been decreasing in developed countries over the past two decades, both are increasing in developing nations. $(1,7)$

ROP is a multifactoral, vasoproliferative disorder of the developing retina of preterm neonates and can progress to a tractional retinal detachment. In the more severe forms,

S. Tzvetkova, Dept of Obstetric and Gynecology, University of Medicine, 55 Marin Drinov St., BG-9002, Varna, BULGARIA
ROP results in a important visual impairment or blindness, both of which carry a high financial cost for the community, but also a high individual cost by affecting the normal motor, language, conceptual and social development of the child. $(2,11,20)$

The Global Initiative for the Elimination of Avoidable Blindness and the World Health Organization's Vision 2020 program targets ROP as a "avoidable disease" requiring early detection, prevention and treatment in an effort to reduce the prevalence of childhood blindness.

Screening for ROP detect infants needing treatment for ROP and decrease the risk of most severe forms. The variations in national and general health care, socioeconomic factors, criteria for treatment of ROP make necessary to adapt screening programs to each country and revise them regulary. $(13,24)$ 


\section{OBJECTIVE}

The aim of this study is to review the antenal and postnatal risk factors, associated with ROP, evaluate the current screening guidelines in our neonatal intensive care unit and present the results of his application.

\section{MATERIALS AND METHODES}

864 infants with a birth weight of less than $2000 \mathrm{~g}$. were admited to the Neonatal Intensive Care Unit of the Hospital of Gynecology and Obstetric-Varna from 1996 to 2005. Our unit has tertiary neonatal care level with a capacity of 10 beds, and is a regional referral neonatal intensive care center for Varna region.

Infants were screened for ROP by an ophthalmologist, using direct ophthalmoscope after dilating the pupils with Mydrum eye drops. We follow the protocol of examing the preterm infants at four weeks of postnatal age. The criteria to include in the screening are:

- birth weight less than $1500 \mathrm{~g}$.;

- gestational age less than 32 weeks;

- all neonates between $1500-2000 \mathrm{~g}$. and $>32$ weeks who required supplemental oxygen therapy $+/$ mechanical ventilation for more than 7 days.

If ROP was not detected at the initial examination, the infants were reevaluated once every 10 days until full retinal vascularization and then every four weeks until six mounths of postnatal age. If ROP was detected, the examination were performed every week until the disease started to regress.

The changes of ROP were classifed according to the International Classification of Retinopathy of Prematurity.

- Stage 1. Demarcation - line separating the avascular retina anteriorly from the vascularized retina posteriorly with abnormal branching of small vessels immediately posterior to this.

- Stage 2. Intraretinal ridge: the demarcation line has increased in volume, but this proliferative tissue remains intraretinal.

- Stage 3. Ridge with extraretinal fibrovascular proliferation.

- Stage 4. Partial retinal detachment.

- Stage 5. Total retinal detachment.

Threshold ROP was defined as the presence of at least eight cumilative $30^{\circ}$ sectors (clock hours) of stage 3 , or at least five contiguous $30^{\circ}$ sectors of stage 3 of extraretinal neovessels in the presence of disease. This is also defined as the presence of dilated tortuons vessels in the posterior pole ("plus disease"). $(1,2,11)$

Patients data were collected retrospectively and the following neonatal risk factors were identified: birth weight, gestational age, Apgar score of less than five at five minutes, oxygen therapy and maximum concentration of inspired oxygen, mechanical ventilation, pathology of the neonate as intraventricular hemorrage (IVH), RDS, neonatal sepsis.
The following maternal factors were identified: antepartum haemorrhage, preeclampsia, premature rupture of membranes.

Cryotherapy for ROP was done in Hospital of Ophthalmology-Varna or in the neonatal unit. Those infants were then followed up weekly until the regression of the disease.

\section{RESULTS}

Over the ten years period from $1996-2005,686$ neonates were screened for the presence of ROP. The total number of ROP cases was $143(20,85 \%)$, there were 77 male and 66 female infants.

We compare the results of screening examinations for two study periods: from $1996-2000$ and from $2001-2005$.

A total of 138 infants had the disease in both eyes, two had in the left eye and three infants in the right eye only.

Mild ROP (stages 1 and 2) was found in 7,14\% (49/686) and severe ROP (stages $3-5)$ in 13,7\% (94/686) of the examined infants.

Table 1 shows the distribution of injured eyes, according the severity of ROP

Table 1 Distribution of injured eyes, according the severity of $R O P$

\begin{tabular}{||l|c|c|c|c||}
\hline \hline \multirow{2}{*}{$\begin{array}{c}\text { Severity of } \\
\text { ROP }\end{array}$} & \multicolumn{2}{|c|}{$\mathbf{1 9 9 6 - 2 0 0 0}$} & \multicolumn{2}{|c||}{ 2001-2005 } \\
\cline { 2 - 5 } & n-eyes & $\mathbf{\%}$ & n-eyes & $\%$ \\
\hline $\begin{array}{l}\text { Severe ROP } \\
\text { (stage 13-5) }\end{array}$ & 77 & 68,75 & 111 & 65,68 \\
\hline $\begin{array}{l}\text { Mild ROP } \\
\text { (stage 1-2) }\end{array}$ & 35 & 31,25 & 58 & 34,32 \\
\hline Total & 112 & & 169 & \\
\hline
\end{tabular}

\section{Chi-test -0,59}

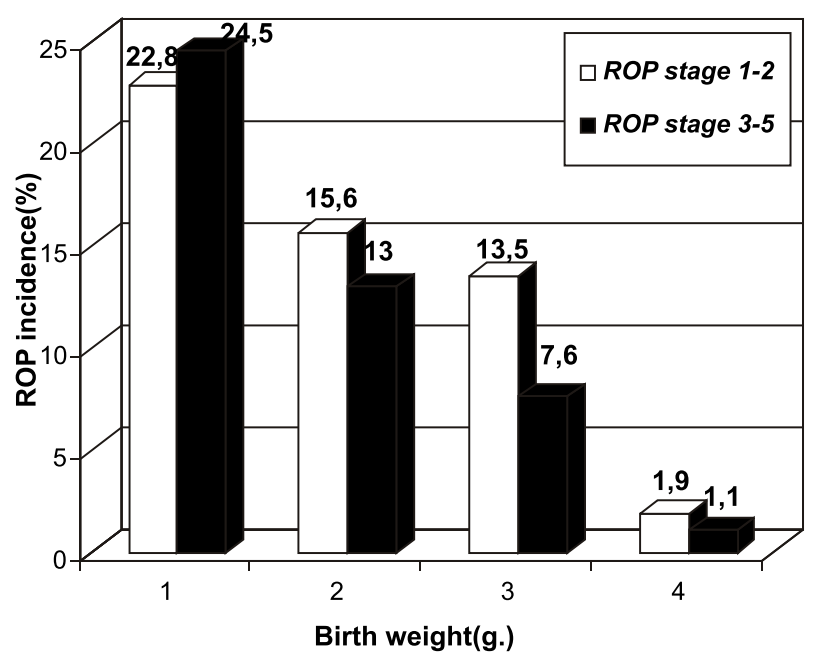

Fig. 1 Incidence of ROP by birth weight specific groups neonates: $1 . \leq 1000$ g. 2. 1000-1250g. 3. 1250-1500g. 4. $\geq 1500 \mathrm{~g}$. 
The frequency of the severe forms of the disease is not changed significantly in the two five-years periods.

Many authors at the last 20 years describe the birth weight and the gestational age as the most important risk factors for ROP. Low birth weight is constantly associated with the disease. $(2,3,12,23)$

In our study the mean birth weight of infants was $1368 \mathrm{~g}( \pm$ $343)$ for the first period and $1271 \mathrm{~g}( \pm 303)$ for the second and the gestational age was $30 \pm(2)$ weeks for the both periods.

The incidence of ROP by birth weight specific groups of infants is shown in fig.1.

Some of the factors that precipitate ROP may occur before birth. Chronic hypoxia in utero, maternal infection, IUGR are prenatal conditions that seem to be related to the development of ROP. It is suspected that as many as one third cases of ROP are caused by prenatal rather than postnatal conditions.

We found some ante- and intrapartal risk factors in 53,6\% of the neonates with different stages of ROP. They include: preeclampsia, maternal infection, antepartum haemorrage, premature rupture of membranes, Apgar score ?5 at $5 \mathrm{~min}$. The neonatal and maternal risk factors associated with the disease are shown in Table 2.

Table 2 Neonatal and maternal risk factors for ROP
Many possible risk factors for the development of ROP have been postulated including: seizuries, multiple spells of apnea or bradicardia, anaemia, blood transfusions. (4)

These factors may have a direct effect on the risk of ROP, or they may simply be indicators of smaller infants, who are more likely to develop many of the complications of prematurity, including ROP.

Respiratory immaturity with RDS, necessitate longer duration of mechanical ventilation and supplemental oxygen and is related significantly to the incidence and severity of ROP.

Supplemental oxygen is a significant risk factor for ROP. $(10,20,22,23)$

Table 3 represent the time of supplemental oxygen (h), according to oxygen concentrations and mechanical ventilation (h)

When the screening program for ROP started in our NICU in 1996, we accepted the guidelines of AAA from 1992.Because the findings of threshold ROP in babies ? $1500 \mathrm{~g}$. and ? 30 weeks GA, we changed our criteria and in the years after 2000, there was an improvement of the outcomes after cryotherapy. Table 4 shows the outcomes after treatment with cryotherapy

\begin{tabular}{|c|c|c|c|c|c|}
\hline Risk factors & $\begin{array}{c}\text { With ROP } \\
\text { infants -number }\end{array}$ & $\begin{array}{c}(n=143) \\
\%\end{array}$ & $\begin{array}{c}\text { Without ROP } \\
\text { infants -number }\end{array}$ & $\begin{array}{c}(n=543) \\
\%\end{array}$ & OR \\
\hline RDS & 104 & 72,7 & 298 & 54,8 & 2,66 \\
\hline Apgar score $\leq 5$ at $5 \mathrm{~min}$. & 44 & 30,76 & 141 & 25,96 & 1,26 \\
\hline IVH gr.III-IV & 50 & 34,96 & 109 & 20,07 & 2,14 \\
\hline DAP & 35 & 24,47 & 156 & 28,7 & \\
\hline Maternal-fetal infections & 44 & 30,76 & 176 & 32,41 & 0,93 \\
\hline Mecanical ventilation & 74 & 51,74 & 198 & 36,46 & 1,86 \\
\hline Maternal preeclampsia & 31 & 21,68 & 128 & 23,57 & 0,89 \\
\hline Premat. rupture of membranes & 48 & 33,56 & 197 & 36,27 & 0,88 \\
\hline
\end{tabular}

Table 3 Time of supplemental oxygen (h) and mechanical ventilation (h)

\begin{tabular}{|c|c|c|c|c|}
\hline $\mathrm{FiO}_{2}$ & $\begin{array}{l}1996-2000 \\
\text { Mild ROP }\end{array}$ & Severe ROP & $\begin{array}{l}2001-2005 \\
\text { Mild ROP }\end{array}$ & Severe ROP \\
\hline$\geq 70 \%$ & 15,25 & 44,2 & 23,8 & 44,5 \\
\hline $30-69 \%$ & 84 & 96,4 & 64,5 & 102,6 \\
\hline$\leq 30 \%$ & 349,5 & 397 & 219,9 & 380,9 \\
\hline Total time of suppl. oxygen & 448,7 (18,6 days) & 538 (22,4 days) & 300 (12,5 days) & 528 (22 days) \\
\hline Mean time of mech. ventilation & 163,4 & 161,4 & 115 & 173 \\
\hline
\end{tabular}


Table 4 Outcomes after treatment with cryotherapy

\begin{tabular}{|c|c|c|c|c|c|c|}
\hline \multirow{2}{*}{$\begin{array}{l}\text { Cryotherapy } \\
\text { outcome }\end{array}$} & \multicolumn{2}{|c|}{$1996-2000$} & \multicolumn{2}{|c|}{ 2001-2005 } & \multicolumn{2}{|c|}{ 1996-2005 } \\
\hline & n-eyes & $\%$ & n-eyes & $\%$ & n-eyes & $\%$ \\
\hline favourable & 45 & 58,44 & 96 & 86,49 & 141 & 75 \\
\hline unfavourable & 32 & 41,56 & 15 & 13,51 & 47 & 25 \\
\hline total & 77 & & 111 & & 188 & \\
\hline
\end{tabular}

Chi-test - 0,00001260

\section{DISCUSSION}

ROP is a multifactorial disease. Several factors increase the risk of ROP and especially those associated with short gestation and low birth weight. Other identified risk factors include sepsis, IVH, oxygen therapy and mechanical ventilation. Although supplemental oxygen is a significant risk factor for ROP. The altered regulation of vascular endothelial growth factor from repeated episodes of hyperoxia and hypoxia is one important factor in the pathogenesis of ROP. Strict oxygen management of the fraction of inspired oxygen $\left(\mathrm{FiO}_{2}\right)$ and the monitoring of 02 saturation parameters may be associated with decreased rates of ROP. $(7,9,10,12,25)$

ROP begins to develop between 32 and 34 weeks after conception, regardless of gestational age at delivery, and has two distinct phases. During the acute first phase, the normal vasculogenesis of the retina is disturbed by the relative hyperoxia of the extrauterine environment. They causes vasoobliteration and nonvascularisation of some areas of the anterior retina. The subsequent hypoxia causes a second chronic phase, characterised by the proliferation of vascular and glial cells, arteriovenous shunt formation, occasionally leading to involution or cicatrical changes and visual impairment. (14)
A number of other risk factors have been suggested as contributors to ROP although it is unclear whether these are truly independent risk factors or simply indicators of the compromised health of the neonate. These factors include bronchopulmonary dysplasia, number of blood transfusions, parenteral nutrition, hypo/hypercarbia, early intubation, hypotension, patent ductus arteriosus, necrotising enterocolitis, administration of $Я$ blockers to mothers before delivery, intraventricular haemorrhage, poor postnatal weight gain. $(4,5,10,22)$

The incidence of ROP and the severity of the disease are not changed significantly in the two five-years periods, but the study's 10 years follow-up report confirmed these lasting benefits: unfavorable structural outcomes were reduced from $41,56 \%$ to $13,51 \%$.

We note that the long duration of the study period during which significant advances have been made in the treatment protocol of VLBW could have influenced our results. The main goal was to minimize repeated episodes of alternating hypoxia/hyperoxya by modifying the practice of wide fraction of inspired oxygen $\left(\mathrm{FiO}_{2}\right)$ and to avoid undesired episodes of high oxygen saturation levels as measured by pulse oximetry $\left(\mathrm{SpO}_{2}\right) .(11,14,15)$

Accepted values in $\mathrm{SpO}_{2}$ were $95-100 \%$ for all babies in the first period during 1996 - 2000. Those saturation goal

Table 5 Screening criteria for ROP

\begin{tabular}{||l|c|c|c|c||}
\hline \hline Screening criteria & $\begin{array}{c}\text { Supplemental oxygen }+/- \\
\text { Gest.age (weeks) }\end{array}$ & $\begin{array}{c}\text { Birth weight } \\
\mathbf{t}(\mathbf{g})\end{array}$ & $\begin{array}{c}\text { Supplemental oxygen } \\
\text { Birth weight(g) }\end{array}$ & I examination/w \\
\hline AAP, 1992 & $\leq 30$ & $\leq 1250$ & $\leq 1800$ & $5-7$ \\
\hline AAP, 2001 & $\leq 28$ & $\leq 1500$ & $1500-2000 / \geq 32$ with instable clinical course & $4-6 / 31-33$ PMA \\
\hline AAP, 2005 & $\leq 32$ & $\leq 1500$ & $1500-2000 / \geq 32$ with instable clinical course & $4-9$ \\
\hline Canada & $\leq 29$ & $\leq 1250$ & $\geq 1250 / \geq 29$ with instable clinical course & $5-7 / 31-33$ PMA \\
\hline Varna, 1996 & $\leq 34$ & $\leq 2000$ & $\leq 2500$ & $5-7$ \\
\hline Varna, 2001 & $\leq 32$ & $\leq 1500$ & $\leq 2000 / 1 \geq 32$ with instable clinical course & 4 \\
\hline \hline
\end{tabular}


limits were changed and after 2001 supplemental oxygen was given to maintain pulse oximetry $\mathrm{SpO}_{2}$ between 90 and 95\%.

As our understanding of ROP increases, screening guidelines are altered. Table 5 present the screening criteria for ROP accordingly different guidelines

In the last years some guidelines recommend that examinations be limited to neonates, born more prematurely but expands the criteria to include infants with higher birth weight regardless of clinical course. $(3,8,13,16,17)$

Treatment of ROP is associated with a $41 \%$ decrease in the occurrence of posterior retinal traction or detachments and a $19 \%$ to $24 \%$ decrease in the incidence of blindness. Because of the sequential nature of the progression of the disease, the proven benefits of cryotherapy demand carefully timed retinal examinations of at-risk preterm neonates for ROP to minimize the risk of visual loss by those infants. $(14,18,19)$

\section{CONCLUSION}

The rate of severe ROP and the need for therapy decrease significantly in association with the use of adequate pulse oxymetry monitoring equipment and the implementation of a strict clinical practice of oxygen administration and management in infants with birth weight of less than $1500 \mathrm{~g}$.

Screening program and guidelines for ROP were applied in our neonatal intensive care unit 10 years ago. They were based on an epidemiological study on the incidence of ROP and other international studies. We consider that our experience can be use for the elaboration of national screening guidelines

The goal of an effective screening program must be to identify the relatively few preterm infants who require treatment for ROP from among the much number born, while minimizing the number of stressful examination required for these infants.

Examination for ROP should be performed by an ophthalmologist with sufficient regular experience and knowledge in the examination of preterm infants for ROP.

Unit - specific criteria for examination for ROP should be established for each neonatal intensive care unit by consultation and agreement between neonatology and ophthalmology services.

\section{REFERENCES}

1. American Academy of Pediatrics (Section on Ophthalmology): Screening Examination of Premature Infants for Retinopathy of Prematurity - Pediatrics Vol.108 N3 September 2001, pp.809-811

2. American Academy of Pediatrics: Screening Examination of Premature Infants for Retinopathy of Prematurity - Pediatrics Vol.111 N2 February 2006, pp.572-576
3. Andruscavage L., D. Weissgold. Screening for retinopathy of prematurity-British Journal of Ophthalmology 2002;86:1127-1130

4. Engelbert JA., RA. Saunders, D. Purohit, TC Hulsey, M. Ebeling. The effect of anemia on retinopathy of prematurity in extremely low birth weight infants - J Perinatol. 2001

Jan-Feb;21(1):21-26

5. Friling R., SD Rosen, T. Monos, M. Karplus, Y. Yassur. Retinopathy of prematurity in multiple gestation, very low birth weight infants - J.Pediatr Ophthalmol Strabismus 1997 Mar-Apr;34(2):96-100

6. Gaugler C., J.Beladdale, D. Astruc, D. Schaffer, L. Donato, U. Simeoni, J. Messer. of Retinopathy of Prematurity: 10-year retrospective study at tke University Hospital of Strasbourg - Arch Pediatr. 2002 Apr;9(4):350-7

7. Gilbert C., A.Fielder, L.Gordillo, R.Semiglia. Characteristics of infants with severe retinopathy of prematurity in contries with low, moderate and high levels of development:implications for screening programs - Pediatrics Vol.115 N5 May 2005, pp e518-e525

8. Haines L., A.Fielder, Baker H., Wilkinson AR. UK population based study of severe retinopathy of prematurity: screening, treatment and outcome -Archives of Disease in Childhood Fetal and Neonatal edition 2005; 90:F240-F244

9. Higgins RD., AL Mendelsohn, MJ DeFeo, R. Ucsel. Antenatal dexamethasone and decreased severity of Retinopathy of Prematurity - Arch Ophthalmol.1998May;116 (5):601-5

10. Holmstrom G., U.Broberger, P. Thommassen. Neonatal risk factors for retinopathy of prematurity a population based study - Acta Ophthalmol Scand. 1998 Apr;76(2):204-7

11. Hussain N., Clive J., Bhandari V. Current Incidence of Retinopathy of Prematurity - Pediatrics Vol.104 N3 September 1999, pp e26-e32

12. Kim TI., J. Sohn, YH. Yoon. Postnatal risk factors of retinopathy of prematurity - Paediatr Perinat Epidemiol. 2004 Mar; 18(2):130-4

13. Larsson E., G. Holmstrom. Screening for retinopathy of prematurity: evaluation and modification of guidelines - British Journal of Ophthalmology 2002;86:1399-1402

14. Lily C., W. Kenneth, A. Sola. Can changes in Clinical Practice Decrease the Incidence of Severe Retinopathy of Prematurity in Very Low Birth Weight Infants - Pediatrics Vol.111 N2 February 2003, pp 339-345

15. Mc Gregor M., D. Bremer, C. Cynthia, R. McClead, D. Phelps, R. Fellows, N. Olden. Retinopathy of Prematurity Outcome in Infants with Prethreshold Retinopathy of Prematurity and Oxygen Saturation? 94\% in Room Air: The High Oxygen Percentage in Retinopathy of Prematurity - Pediatrics Vol.107 N4 April 2000, pp 663-668

16. Reynolds JD., V. Dobson, GE. Quinn, AR Fielder, EA Palmer, RA Saundsrs, RG Hardy, CRYO-ROP and LIGHT- ROP Cooperative study Evidence-based screening criteria for Retinopathy of Prematurity: natural history data from the 


\begin{abstract}
CRYO-ROP and LIGHT- ROP studies - Arch Ophthalmol. 2002 Nov;120(11):1470-6
\end{abstract}

17. Subhani M., A. Combs, P. Weber, C. Gerontis. Screening guidelines for Retinopathy of Prematurity: The Need for Revision in Extremely Low Birth Weight Infants - Pediatrics Vol.107 N4 April 2001, pp 656-659

18. Mazen Al-Essa, R.V. Azad. Threshold Stage of Retinopathy of Prematurity: Maternal and Neonatal Risk Factors - Acta of Saudi Medicine Vol.20.N2.2000

19. Onofrey CB., WJ Feuer, JT Flynn. The outcome of Retinopathy of Prematurity: Screening for retinopathy of prematurity using an outcome predictive program - Ophthalmology 2001 Jan;108(1):27-34

20. Padmani K., J.Muttineni, L. Angell, W. Karmaus. Retinopathy of Prematurity and risk factors: prospective cohort study $-B M C$ Pediatrics 2005, 5:18

21. Rowlands E., AC Ionides, S. Chinn, H. Mackinnon, C. Davey. Reduced incidence of
Retinopathy of Prematurity - Br J Ophthalmol. 2001; 85:933-935 (August)

22. Seiberth V., O. Linderkamp. Risk factors in Retinopathy of Prematurity: a multivariate statistical analysis - Ophthalmology 2000 Apr;214(2):131-5

23. Vyas J., D. Field, E. Draper, G. Woodruff, A. Fielder, J. Thompson, N. Shaw, D. Clarck, R. Gregson, J. Bruke, G. Durbin. Severe Retinopathy of Prematurity and its association with different rates of survival in infants of less than $1251 \mathrm{~g}$ birth weight - Archives Dis in Child Fetal and Neonatal ed 2000; 82:F145-F149 (March)

24. Wheatley C., J.L. Dickinson, D. Mackey, J.E. Craig, M.M. Sale. Retinopathy of Prematurity - recent advances in our understanding Archives of Disease in Childhood Fetal and Neonatal edition 2002; 87:F78-F82

25. Watts P., G. Adams, R. Thomas, C. Bunce. Intraventricular haemorrage and stage 3 retinopathy of prematurity - Br.J. Ophtalmol. 2000;84:596-599(June) 